Available online at GSC Online Press Directory

GSC Advanced Research and Reviews e-ISSN: 2582-4597, CODEN (USA): GARRC2

Journal homepage: https://www.gsconlinepress.com/journals/gscarr

(RESEARCH ARTICLE)

\title{
Patient's backgrounds, perceptions toward a primary medical centers and reasons in getting medical services at general clinic in the provincial hospital
}

\author{
Chearasatawong Nattawon ${ }^{1}$, Bosittipichet Tatree ${ }^{2}$ and Leesri Thanakamon ${ }^{3, *}$ \\ ${ }_{1}^{1}$ Department of social medicine, Saraburi hospital 18 Thesaban 4 Road, Pak Phriao Subdistrict, Mueang Saraburi \\ District, Saraburi 18000, Thailand. \\ ${ }^{2}$ Department of Social Medicine, Phra Nakhon Si Ayutthaya Hospital 46/1 U-Thong Rd. Pratoochai sub-district Phra \\ Nakhon Si Ayutthaya district Phra Nakhon Si Ayutthaya 13000 Thailand. \\ ${ }^{3}$ Department of Community Health Nursing, Institute of Nursing, Suranaree University of Technology 111 University \\ Avenue Suranaree Subdistrict, Muang Nakornratchasima 30000, Thailand.
}

Publication history: Received on 13 March 2020; revised on 19 March 2020; accepted on 21 March 2020

Article DOI: https://doi.org/10.30574/gscarr.2020.2.3.0020

\begin{abstract}
Primary health care system takes important role in citizen heath care with abundant of primary care unit near citizen residents in order to solve barrier of distant region health care accessibility problem and appropriate referral system. This research objectives are to study patient characteristics, primary care unit acknowledgement and reason for visiting in general practice outpatient department, result of health care service and traveling details including distance time and money cost of journey to receive health care service. A descriptive cross-sectional study collecting data from 343 patients in sample group with government universal coverage health insurance plan. The result found that $77.84 \%$ of the samples are female and $22.16 \%$ are male with mean age of $56.01 \pm 14.67$ year. Majority of samples are freelance general contractor and housekeeper. Average household income was 4,040.06 $\pm 4,536.75$ baht. 54.22\% of patients have at least one underlying disease. $95.59 \%$ of the patients acknowledge their primary care unit and had experience of using the primary care unit. Average distant to the hospital was $12.22 \pm 6.79$ kilometers, average time was $30.39 \pm 12.23$ minutes and average cost was $159.75 \pm 69.42$ baht. Average distant to primary care units was $3.1 \pm 2.63$ kilometers, average time was $13.91 \pm 6.69$ minutes and average cost was $21.86 \pm 33.63$ bath. $99.41 \%$ of the patients were discharge as the result of health care service. The sample group are aware of their own primary care unit but travel to the hospital by choice despite higher cost comparing to cost of traveling to their own primary care unit. The results may be applied to develop strategies for several aspects of primary care unit services and accessibility.
\end{abstract}

Keywords: Patient's background; Perception; Primary Medical Centers; Provincial hospital

\section{Introduction}

Currently, a primary medical center plays a crucial role in the international level, and it is a key aspect in providing health care to residents in a country (1-4). This is because it assists the residents to access health care more conveniently, and they can also get the better medical service. There was an operation of several primary medical centers nearby residential areas. (5) This is to help relieve the commuting expenses for people who live in a distant area and to reduce a hospital overcrowding. One of the aims in founding a primary medical center is to help make a decision in transferring patients to hospitals according to the seriousness of their illness. However, many people choose to get healthcare from a hospital without visiting a primary medical center in their neighborhood first. This problem existed long time ago and persists to occur until nowadays. People, therefore, have to be burdened with expensive commuting expenses, long waiting time and unbearable overcrowding in hospitals. [5-7] This issue continues to exist

\footnotetext{
* Corresponding author: Leesri Thanakamon
}

Copyright (C) 2020 Author(s) retain the copyright of this article. This article is published under the terms of the Creative Commons Attribution Liscense 4.0. 
despite the fact that there are several primary medical centers and local promoting health hospitals in different regional parts of Thailand, and in fact, this primary service can help Thai residents to access better medical service. [8-15]

Saraburi Hospital provides primary healthcare service in a form of general clinics and primary medical centers under the operation of Saraburi Hospital, including medical centers in Muang District such as Family Practice Clinic, Municipal Hospital, Community Medical Centers in Kheha, Khao Khuba and Wat Cheng Khao and medical centers outside Muang District such as promoting health hospitals.[16] However, it is found that General Clinic at Saraburi Hospital is still burdened with a large number of visitors from various areas, and instead of getting primary healthcare from primary medical centers or promoting health hospitals in their areas first, these visitors often go straight to the hospital. According to 2018 Budget [17], it is found that while there were only 24,515 visitors who received medical service from promoting health hospitals in their areas, there were 94,188 visitors who went straight to Saraburi Hospital. Regarding to the number of visits, there were only 95,434 visits at promoting health hospitals whereas there were 418,946 visits at Saraburi Hospital. These numbers are quite large because based on the estimated efficiency of General Clinic, the daily maximum number of visitors that the clinic can provide service to should be 60 . However, nowadays there are approximately 60-80 visitors per day, which are the healthcare coverage around 20 persons per day.

Despite the advancement of transportation in these days, many people still find that topography could pose them some difficulties [13, 18-21]. The issues are also included distance, time and expenses in commuting. However, there are a greater number of people who prefer to get medical service from the hospitals and only fewer people who access primary medical centers in their neighborhood first [10,12-14]. Consequently, this leads to overcrowding in the hospitals. In addition, due to certain reasons, people find that there are some differences of the resource provided by primary medical centers and that of hospitals $[11-14,21]$. They also feel that doctor's performances and diagnosis rounds are different in each context. Moreover, each visitor has different opinions in getting medical service from the hospitals [6]. For example, some people claim that they go to hospital because they want to be investigated by a doctor, and they are informed that a doctor only makes a visit at health promoting hospitals only 1-2 times per month. Hence, they are afraid that if they go to health promoting hospitals when a doctor is not there, they will be investigated by a nurse practitioner. On the other hand, if they go straight to a hospital, it is certain that they will be diagnosed by a doctor. Several preferences also caused by the fact that there are some medical tools, investigation or medicine which are available only at a hospital.

To study patient's backgrounds, perceptions toward primary medical centers or promoting health hospitals in their neighborhood and reasons in getting medical service at General Clinic in Saraburi Hospital. The objective of study also includes the study of the outcomes of medical service and details regarding the commute such as distance, time and expenses.

\section{Methodology}

\subsection{Research design}

This is a descriptive cross sectional study, and the data are collected and analyzed according to the objectives.

The samples in this study are Universal Health Coverage Service insured patients who aged 18 or older and made a visit at General Clinic in Saraburi Hospital during October 2018 -March 2019. The total number of samples is 343. The size of sample group is calculated by Yamane formula, by $\mathrm{N}=2,400$. This comes from the average number of visitors 20 persons per days and 20 days per month throughout 6 months of data collection.

\subsection{Research instruments}

A Tool includes a questionnaire created by the researcher through literature review. The questionnaire can be divided into two sections. The first section includes 7 inquiries regarding to participant's general data while the second section includes 11 inquiries regarding to their access to medical service. The contents of this questionnaire were investigated and approved for its accuracy by two senior officers.

\subsection{Research processes}

In data collection process, a meeting is held to provide information to two officers at General Clinic in Saraburi Hospital. These two officers are appointed to collect data and provide information regarding the questionnaire to the 
participants. The participants can freely fill in the questionnaire, and they can ask the officers any questions they may have.

Descriptive statistics such as percentage, average number and standard deviation are used to analyze and present patient's general data and factors stated in the objectives.

\subsection{Right to Protection and Research Ethics}

This study has been approved by the committee of research ethics regarding to human study of Saraburi Hospital. (The number of project: EC009/2563. signed at 12 March 2019).

\section{Results}

This study is conducted by collecting data from 343 participants who are eligible, determined by the inclusive criteria, and the analysis of a survey will be stated below.

Table 1 General Information

\begin{tabular}{|c|c|c|}
\hline Basic Information & Number & Percentage \\
\hline \multicolumn{3}{|l|}{ Sex } \\
\hline Male & 76 & 22.16 \\
\hline Female & 267 & 77.84 \\
\hline \\
\hline $18-35$ ปี & 40 & 11.66 \\
\hline $36-44$ & 28 & 8.16 \\
\hline $45-59$ & 123 & 35.86 \\
\hline $60-70$ ปี & 106 & 30.90 \\
\hline$>71$ & 46 & 13.41 \\
\hline Mean \pm SD & 56.01 & 14.67 \\
\hline \multicolumn{3}{|l|}{ Occupation } \\
\hline General contactor & 130 & 37.90 \\
\hline Housekeeper & 101 & 29.45 \\
\hline Merchant/Seller & 49 & 14.29 \\
\hline Farmer & 26 & 7.58 \\
\hline Officer & 5 & 1.46 \\
\hline Personal business & 5 & 1.46 \\
\hline Students & 2 & 0.58 \\
\hline unemployed & 25 & 7.29 \\
\hline \multicolumn{3}{|c|}{ Incomes/month (Baht) } \\
\hline$<1,000$ & 80 & 23.32 \\
\hline $1,000-4,999$ & 143 & 41.69 \\
\hline $5,000-9,999$ & 94 & 27.41 \\
\hline $10,000-15,000$ & 20 & 5.83 \\
\hline$>15,000$ & 6 & 1.75 \\
\hline Mean \pm SD & $4,040.06$ & $4,536.75$ \\
\hline \multicolumn{3}{|l|}{ Education } \\
\hline$<$ Bachelor degree & 338 & 98.54 \\
\hline Bachelor degree & 4 & 1.17 \\
\hline > Bachelor degree & 1 & 0.29 \\
\hline \multicolumn{3}{|l|}{ Disease } \\
\hline None & 157 & 45.77 \\
\hline Underlying disease & 186 & 54.22 \\
\hline 1 disease & 120 & 34.99 \\
\hline 2 diseases & 44 & 12.83 \\
\hline
\end{tabular}




\begin{tabular}{lll}
\hline \multicolumn{1}{c}{3 diseases } & 22 & 6.41 \\
Underlying disease & 157 & 45.77 \\
$\quad$ None & 59 & 17.20 \\
Hypertension & 53 & 15.45 \\
Dyslipidemia & 49 & 14.29 \\
$\quad$ Diabetes mellitus & 13 & 3.79 \\
$\quad$ Asthma & 13 & 3.79 \\
GERD/Dyspepsia & 11 & 3.21 \\
Coronary heart disease & 8 & 2.33 \\
Allergic rhinitis & 8 & 2.33 \\
Thyroid disease & 7 & 2.04 \\
CoPD & 5 & 1.46 \\
Anemia & 4 & 1.17 \\
Cirrhosis/Hepatitis B & 4 & 1.17 \\
Rheumatoid arthritis & 3 & 0.87 \\
Benign prostatic hyperplasia & 3 & 0.87 \\
Chronic kidney disease & 2 & 0.58 \\
Gount & 2 & 0.58 \\
Migraine & 2 & 0.58 \\
Stroke & 1 & 0.29 \\
Bipolar disorder & 1 & 0.29 \\
Breast cancer & 1 & 0.29 \\
Epilepsy & 1 & 0.29 \\
Psoriasis & & \\
\hline
\end{tabular}

According to Table 1 , it is found that the majority of participants are females $(77.84 \%)$, while $22.16 \%$ of them are males. Regarding to age, the largest proportion is those aged 45-59 (35.86\%), and this is followed by those aged 60-70 (30.90\%). The average age of participants is at $56.01 \pm 14.67$ years old. In terms of occupations, most of the participants are a general employee (37.90\%) while those who are a housemaker account for $29.45 \%$. Also, people with other occupations make up for $32.66 \%$. Regarding to the amount of income, people whose households gain 1,000-4,999 baht per month account for 41.69 , while there are only $27.41 \%$ who claim that their households gain $5,000-9,999$ baht per month. The average monthly income is at $4040.06 \pm 4,536.75$ baht. In terms of education, $98.54 \%$ of participants are not bachelor graduates while $1.46 \%$ of them hold a bachelor degree or higher. Regarding to chronic disease, $45.77 \%$ of participants report that they have no chronic disease while $34.99 \%$ of them have one chronic disease. The most common chronic diseases are high blood pressure, dialysis and diabetes at $17.20 \%, 15.45 \%$ and $14.29 \%$ respectively. Meanwhile, $19.24 \%$ report that they have 2 chronic diseases or more.

Table 2 Perception of primary care unit

\begin{tabular}{lll}
\hline Acknowledgement & $\mathbf{n = 3 4 3}$ & Percentage \\
\hline Perceive and experience with service & 321 & 95.59 \\
Perceive and not experience with service & 20 & 5.83 \\
No perceive and not experience with service & 2 & 0.58 \\
\hline
\end{tabular}

Table 2 reveals data regarding to an awareness of a primary medical center. 95.59\% of participants are aware of a primary medical center in their areas, and they have accessed the center before. Meanwhile, $5.83 \%$ of them know about 
a primary medical center, but they have never made a visit there. Only $0.58 \%$ of them are not aware of a primary medical center in their areas.

Table 3 Number of patients from different districts whom visit general practice outpatient department Saraburi hospital without referral service from their own primary care unit

\begin{tabular}{lll}
\hline District & $\mathbf{N}=\mathbf{3 4 3}$ & Percentage \\
\hline Mueang Saraburi & 141 & 41.11 \\
Chaloem Phra Kiat & 70 & 20.41 \\
Nong Khae & 74 & 21.57 \\
Kaeng Khoi & 53 & 15.45 \\
Sao Hai & 4 & 1.17 \\
Other & 1 & 0.29 \\
\hline
\end{tabular}

Table 3 represents districts where most of participants, who go straight to General Clinic in Saraburi Hospital without visiting a primary medical center, come from. It is found that $41.11 \%$ of participants com from Muang District, while $58.89 \%$ of them are from other districts. The details regarding to primary medical centers in each district can be found in the first diagram.

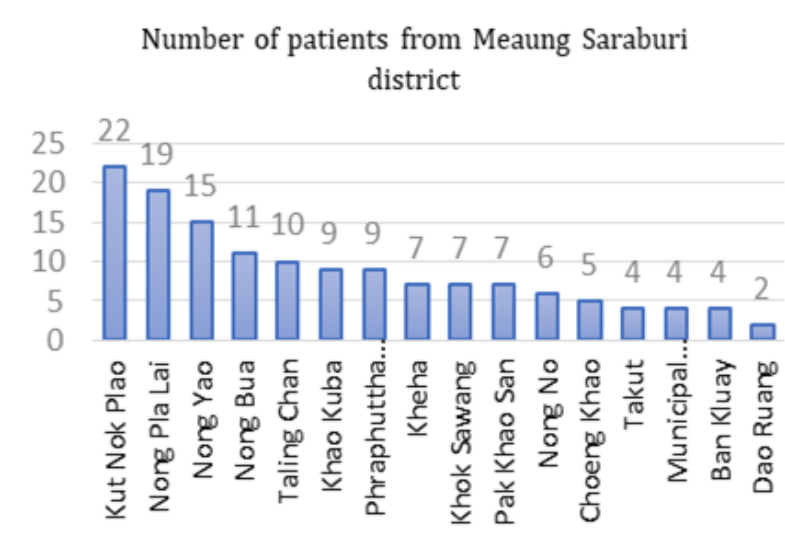

Number of patients from Kaeng Khoi district

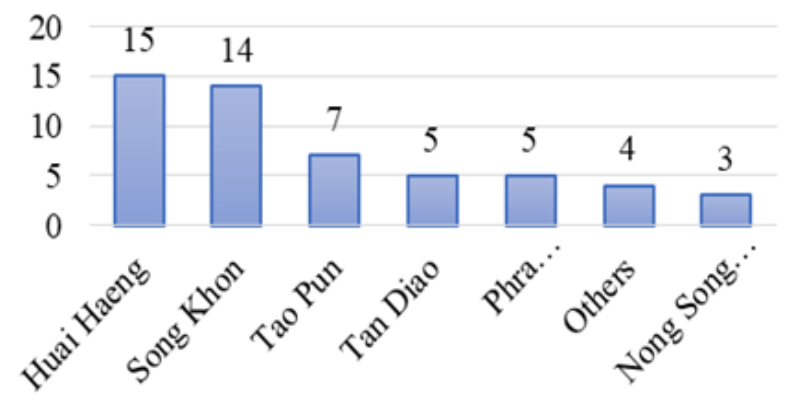

Number of patients from Chaloem Phra Kiat district

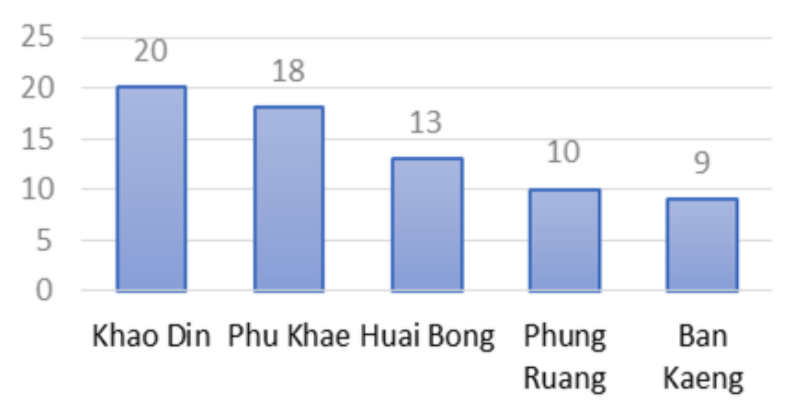

Number of patients from Nong Khae district

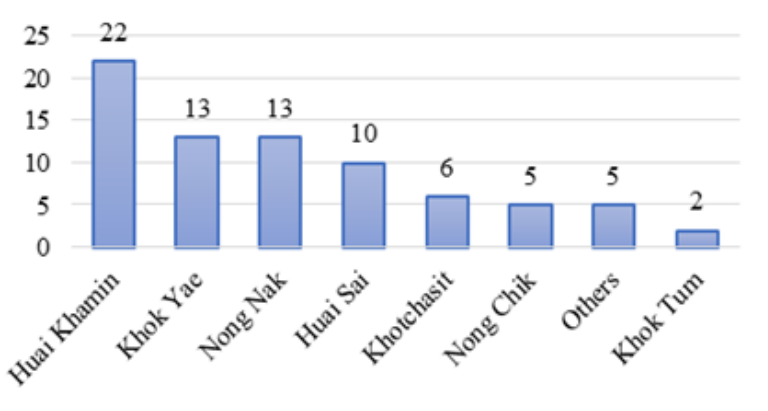

Figure 1 Bar graph demonstrated the number of patients from different primary care setting 
Table 4 Reasons of patient whom visit general practice outpatient department Saraburi hospital

\begin{tabular}{lll}
\hline Reasons for service visit $(\mathbf{n}=\mathbf{3 4 3})$ & Frequency & Percentage \\
\hline Perception of traveling to the hospital is more convenient & 258 & 75.22 \\
Primary care units instruct to directly travel to the hospital & 107 & 31.20 \\
Primary care units have insufficient medical supplies/tools & 66 & 19.24 \\
Primary care units have no doctor at the time of patients' visits & 49 & 14.29 \\
Patients are not informed of their corresponding primary care units & 8 & 2.33 \\
Perception of severe symptoms suggested direct hospital visit & 6 & 1.75 \\
Desire of specific disease examination & 4 & 1.17 \\
Perception of unresolved/unimproved symptoms suggested direct hospital visit & 3 & 0.87 \\
Unsatisfaction of primary care unit personnel/staff & 2 & 0.58 \\
Perception of medicine from hospital superior to primary care unit & 2 & 0.58 \\
Satisfaction of hospital service & 1 & 0.29 \\
\hline
\end{tabular}

Table 4 indicates the reasons why the participants prefer to getting medical service from General Clinic in Saraburi Hospital. $75.22 \%$ of participants state that the commute to the hospital is convenient while $31.20 \%$ of them said that their primary medical centers suggest them to go straight to the hospitals. Meanwhile, $0.58 \%$, or 2 out of all participants, reported that they are not satisfied with the medical service given at their primary medical centers.

Table 5 Details of traveling for service accessibility

\begin{tabular}{lll}
\hline Traveling details & Mean & SD \\
\hline Average distant from household to the hospital (kilometer) & 12.22 & 6.79 \\
Average distant from household to the primary care unit (kilometer) & 3.1 & 2.63 \\
Average time from household to the hospital (minute) & 30.39 & 12.23 \\
Average time from household to the primary care unit (minute) & 13.91 & 6.69 \\
Average cost from household to the hospital (Baht) & 159.75 & 69.42 \\
Average cost from household to the primary care unit (Baht) & 21.86 & 33.63 \\
\hline
\end{tabular}

Table 5 illustrates the details about the commute to Saraburi Hospital. The average distance is 12.22 kilometers, time is 30.39 minutes and expense is 159.75 baht. Regarding to the commute to a primary medical center, The average distance is 3.1 kilometers, time is 13.91 minutes and expense is 21.86 baht.

Table 6 Result of service

\begin{tabular}{lll}
\hline Result of service & Frequency (Patient) & Percentage \\
\hline Discharge & 341 & 99.41 \\
Different department consultation & 1 & 0.29 \\
Admitted to the hospital & 1 & 0.29 \\
\hline
\end{tabular}


Table 6 shows that $99.41 \%$ of the participants are discharged from the hospital. Meanwhile, there is only one patient, accounting for $0.29 \%$, who is transferred to get further treatment in other department. Only another $0.29 \%$, or just one patient, is admitted in the hospital.

\section{Discussion}

Regarding to general backgrounds of patients received service from General Clinic in Saraburi Hospital, most of them are female, and they are at around working age to middle age. The minority of them are graduated with a bachelor degree or higher. However, since it is initially in the inclusive criteria that the participants must be insured with Universal Health Coverage Service, it is hard to determine if educational level will similarly play an important role in patients with other insurances. To illustrate, almost all patients with Universal Health Coverage Service are not bachelor graduates, and their household income is relatively low, comparing to the legal minimum wage in Saraburi Province 325 Baht [22]. Only $7.58 \%$ of them have higher income than the minimum wage for monthly workers. It is found that the majority of participants are general employees and homemakers which correspond with their low incomes, while there are $7.29 \%$ of them who are unemployed. Due to their low income, if the participants have to shoulder the wastes on time and money caused by the commute to the hospital, they are more likely to suffer from financial issues.

It is found that there are $54.23 \%$ of participants who have one chronic disease or more, and most of these diseases are non-infectious diseases such as high blood pressure, dialysis, diabetes and so on. Additionally, they are not such a complicated disease that needs to be investigated by a specialized doctor only, and in fact, the patients can initially get an assist from the primary medical centers. The similar percentage, or $45.77 \%$, of the participants have no chronic disease.

The majority of participants are aware of primary medical centers in their residential areas, and they have received the primary medical service there before. However, they decide to go straight to Saraburi Hospital without visiting the primary medical centers for several reasons as stated in Table 4. It is found that most participants who reside in Muang District find that it more convenient for them to commute to the hospital, comparing to those who live in other districts. Similarly, those who live in other districts also mention that convenience in commuting is the key reason why they prefer to get medical service from Saraburi Hospital. The second most common reason is that there are no medical investigation tools and permanent doctors at the primary medical centers. The minority of participants states that they have personal reasons, and two of them mentioned that they are not satisfied with the medical service provided at their primary medical centers. It is possible that many participants might agree with this reason, and providing this information to primary medical centers will help solve the existing issues, the skip in visiting primary medical centers.

Regarding to the commuting details, it is found that the average distance, time and expenses in commuting to Saraburi Hospital are higher than those in commuting to primary medical centers. To illustrate, the average expense in commuting to Saraburi Hospital is 159.75 Baht, which 7.31 times higher than the average expense in commuting to primary medical centers. The majority of participants mention that convenience in commuting is the reason why they prefer to get medical service from the hospital. However, when considering higher time and money that they need to spend on the commute, it conveys that the participants might feel more comfortable to pay additional costs to obtain "convenience" in other senses. If their sense of "convenience" is about how conveniently they can commute, it should be more convenient for them to commute to primary medical centers when considering the aforementioned three factors.

As many of $31.20 \%$ of participants claimed that their primary medical center notifies them to go straight to Saraburi Hospital, so they need to commute a long distance to get medical service from the hospital. In addition, lack of medical tools and no permanent doctors are the reasons why many participants prefer to get healthcare from the hospital.

\section{Conclusion}

From the study, it is found as following details: the $77.84 \%$ of samples are females while $22.16 \%$ of them are males. The average age of participants is at $56.01 \pm 14.67$ years old. The majority of them are general employees and homemakers. Almost all of participants' level of education is under a bachelor degree. The numbers of participants who have and do not have chronic diseases are quite similar. The most common chronic diseases are high blood pressure, dialysis and diabetes. Most of the participants are aware of their primary medical centers and have accessed them before. The majority of them stated that convenience in commuting is the reason why they prefer to get medical service at Saraburi Hospital. Meanwhile, other reasons, including lack of medical tools, no permanent doctors and unawareness of their primary medical centers, account for merely $2.33 \%$ each. 
There should be a reconsideration regarding possible obstacles in getting a medical service and convenience in commuting to a primary medical center in each area. A primary medical center should publicize their general information, services and range of abilities to people in their area, and the center should seek a way to respond to people's health demands. The convenience in commuting to a primary medical center should be improved, and the center should be enabled to supply more medical tools and employ a permanent doctor. This will significantly help decreasing people's possible obstacles in getting medical services from the primary center as well as their burdens in commuting the long distance.

\section{Compliance with ethical standards}

\section{Acknowledgments}

I would like to express my sincere gratitude to the officers at General Clinic in Saraburi Hospital for their support in data collection and to the professors at the Department of Social Medicine in Saraburi Hospital as well as the professors at the Department of Family Medicine in Phra Nakhon Si Ayutthaya Hospital for their advises throughout the process of this study.

\section{Disclosure of conflict of interest}

The authors declared no potential conflicts of interest with respect to the research, authorship, and or publication of this article.

\section{Statement of ethical approval}

As this study involves human subject, it has been approved by the committee of research ethics regarding to human study of Saraburi Hospital, Thailand. (The number of project: EC009/2563. signed at 12 March 2019).

\section{Statement of informed consent}

This study involves information about any individual such as survey, interview. The informed consent was obtained from all individual participants included in the study."

\section{References}

[1] Primary health care in the Western Pacific [Internet]. [cited 2019 Dec 26].

[2] Primary health care [Internet]. [cited 2019 May 13].

[3] Cancino R. (2017). Primary Care Issues in Inner-City America and Internationally. Prim Care Clin Off Pract [Internet], 44(1), 21-32.

[4] Ellner AL and Phillips RS. (2019). The Coming Primary Care Revolution. J Gen Intern Med [Internet], 32(4), 3806.

[5] The Thailand Primary Care System Act 2019 [Internet]. Gazette 2019 [cited 2562 Dec 26].

[6] Pitchsinee Mongkolsiri and Pukkanut wongkodsuwan. (2013). Satisfaction, Perception and Confidence of Clients toward Primary Health Care Service of Udonthani Hospital Primary Health Care Network. Udonthani: Udonthani Boromratchonnanee Nursing Collage.

[7] Hfocus.org Explore of Healthcare System. [Internet]. 2562 [cited 2020 Jan 2].

[8] WHO. (2013). Health workforce contributions to health system development: a platform for universal health coverage [Internet].

[9] Thammatacharee N, Tisayaticom K, Suphanchaimat R, Limwattananon S, Putthasri W, Netsaengtip R, et al. (2012). Prevalence and profiles of unmet healthcare need in Thailand. BMC Public Health, 12(1).

[10] Healthcare Disparities \& Barriers to Healthcare campus Rural Health | Stanford Medicine [Internet]. [cited 2020 Jan 5].

[11] Harfield S, Davy C, Kite E, McArthur A, Munn Z, Brown N, et al. (2015). Characteristics of Indigenous primary health care models of service delivery: a scoping review protocol. Vol. 13, JBI database of systematic reviews and implementation reports, 43-51. 
[12] I kai T, Yamtree S, Takemoto T, Tamura T, Kanayama H, Sato K, et al. (2016).Medical care ideals among urban and rural residents in Thailand: A qualitative study. Int J Equity Health. Jan 5, 15(1).

[13] Thailand: Improved geographic and financial access to care strengthens primary care | PHCPI [Internet]. [cited 2020 Jan 5].

[14] Limwattananon S, Tangcharoensathien V, Tisayaticom K, Boonyapaisarncharoen $\mathrm{T}$ and Prakongsai $\mathrm{P}$. (2012).Why has the universal coverage scheme in Thailand achieved a pro-poor public subsidy for health care? In: BMC Public Health.

[15] Choochai Supphawong, Somsak Chunharats, Ladda Dumrikarnlerd, Supatra Sriwanichakorn, and Kasem Wechsuntranon. (2009).The manual of services in primary care unit. [Ebook]. Bangkok: The National Health Security Office, MOPH.

[16] Kunders GD. (2008).Hospitals : facilities planning and management [Internet]. Tata McGraw-Hill Pub. House, 507.

[17] The Provincial Health Office of Saraburi Province, Thailand. (2019).

[18] Pratt R, Gyllstrom B, Gearin K, Lange C, Hahn D, Baldwin LM, et al. (2018). Identifying Barriers to Collaboration Between Primary Care and Public Health: Experiences at the Local Level. Public Health Rep.

[19] Rocha TAH, Da Silva NC, Amaral PV, Barbosa ACQ, Rocha JVM, Alvares V, et al. (2017). lAddressing geographic access barriers to emergency care services: A national ecologic study of hospitals in Brazil. Int J Equity Health. Aug, 22, 16(1).

[20] Mayer CM, Owaraganise A, Kabami J, Kwarisiima D, Koss CA, Charlebois ED, et al. (2019).Distance to clinic is a barrier to PrEP uptake and visit attendance in a community in rural Uganda. J Int AIDS Soc. Apr, 1, 22(4).

[21] Wang L and Ramroop S. (2018). Geographic disparities in accessing community pharmacies among vulnerable populations in the Greater Toronto Area. Can J Public Heal. Dec 1, 109(5-6), 821-32.

[22] The Gazette. (2019). The announcement from wage committee on the minimum wage rate (Issue 10) 2019. [cited 2563 March 1].

\section{How to cite this article}

Chearasatawong N., Bosittipichet T. and Leesri T. (2020). Patient's backgrounds, perceptions toward a primary medical centers and reasons in getting medical services at general clinic in the provincial hospital. GSC Advanced Research and Reviews, 2(3), 55-63. 